\title{
Vitamin D status in elite Irish athletes
}

\author{
P. J. Magee ${ }^{1}$, L. K. Pourshahidi ${ }^{1}$, L. Leech ${ }^{1}$, J. McFadden $^{1}$, J. M. W. Wallace ${ }^{1}$, J. Conway ${ }^{2}$, \\ E. Harney ${ }^{3}$ and S. M. Madigan \\ ${ }^{1}$ Northern Ireland Centre for Food and Health, University of Ulster, Coleraine, BT52 1SA, ${ }^{2}$ Irish Institute of Sport, \\ Sports Campus Ireland, Abbottstown, Dublin and ${ }^{3}$ Down County Board, Castlewellan, BT31 9DP, UK
}

Recent evidence suggests that vitamin D insufficiency is associated with an increased risk of stress fracture, total body inflammation, infectious illness and impaired muscle function ${ }^{(1,2)}$ and is thus likely to impair the training ability of athletes in addition to affecting their overall health. Though not widely studied, vitamin D deficiency and insufficiency have been reported among athletes, irrespective of geographic location ${ }^{(3)}$. The aim of the current study was to assess vitamin D status in two groups of elite Irish athletes sampled in different months of the year.

Non-fasting blood samples were taken from consenting volunteers ( $n$ 66) and total serum 25-hydroxyvitamin $\mathrm{D}(25(\mathrm{OH}) \mathrm{D})$ was quantified by enzymeimmunoassay (IDS Limited, Boldon, UK). Serum calcium and plasma parathyroid hormone (PTH) concentration were also assessed (using the I-lab 650 Clinical Chemistry analyser and ARCHITECT i1000SR integrated system, respectively).

\begin{tabular}{|c|c|c|c|c|c|c|c|}
\hline & \multicolumn{3}{|c|}{ Paralympians $(n$ 32) } & \multicolumn{3}{|c|}{ Gaelic Footballers $(n$ 34) } & \multirow[b]{2}{*}{$P$ value* } \\
\hline & Median & 25 th & $75^{\text {th }}$ & Median & $25^{\text {th }}$ & 75 th & \\
\hline Sampling month & & November & & & March & & \\
\hline $25(\mathrm{OH}) \mathrm{D}(\mathrm{nmol} / \mathrm{L})$ & 57.44 & 48.60 & 67.23 & 33.35 & 28.76 & 41.58 & $<0.001$ \\
\hline PTH $(\mathbf{n g} / \mathbf{m L})$ & 34.55 & 19.95 & 45.55 & 37.90 & 28.40 & 43.65 & 0.572 \\
\hline $\mathrm{Ca}(\mathrm{mmol} / \mathrm{L})$ & 2.50 & 2.41 & 2.58 & 2.43 & 2.36 & 2.46 & 0.002 \\
\hline Vitamin D intake $(\mu \mathrm{g} / \mathrm{d}) \dagger$ & 5.49 & 2.57 & 8.09 & $\sim$ & $\sim$ & $\sim$ & \\
\hline Calcium intake $(\mathrm{mg} / \mathrm{d}) \dagger$ & 909 & 507 & 1474 & $\sim$ & $\sim$ & $\sim$ & \\
\hline
\end{tabular}

Vitamin D status was significantly lower in the gaelic athletes compared to the paralympians. Moreover, a greater proportion of gaelic athletes had a $25(\mathrm{OH}) \mathrm{D}<50 \mathrm{nmol} / \mathrm{L}$ compared to the paralympians $(94 \%$ vs. $28 \%)$; a level most experts use to define $25(\mathrm{OH}) \mathrm{D}$ deficiency ${ }^{(3)}$. Among the paralympians, the serum $25(\mathrm{OH}) \mathrm{D}$ and calcium concentrations of wheelchair-bound athletes were significantly lower compared to that of their able-bodied counterparts $(P=0.013$ and $P=0.001$, respectively), without significantly affecting PTH concentrations $(P=0.676)$. There were no significant differences in mean daily vitamin $\mathrm{D}(P=0.903)$ or calcium $(P=0.210)$ intakes between the two groups of paralympians. Mean daily vitamin $\mathrm{D}$ and calcium intake were significantly correlated after controlling for age and gender $(r=0.464, P=0.030)$, however were not associated with circulating $25(\mathrm{OH}) \mathrm{D}$, PTH or calcium concentrations.

This study highlights a high prevalence of vitamin D deficiency among elite Irish athletes, particularly at the end of winter. Inadequate sun exposure, rather than diet, is the likely cause of lower $25(\mathrm{OH}) \mathrm{D}$ concentrations observed in the wheelchair athletes. A serum $25(\mathrm{OH}) \mathrm{D}$ concentration $\geq 80 \mathrm{nmol} / \mathrm{L}$ has recently been postulated as desirable for athletes ${ }^{(2)}$ however, the majority of athletes sampled in this study failed to reach this level. Vitamin D supplementation should therefore be considered for these athletic groups.

This study was funded by the Paralympic Council of Ireland and Down County Board. Ethical approval was obtained from the University of Ulster Research Ethics Committee (REC/10/0228) and the study was conducted according to the guidelines laid down in the Declaration of Helsinki.

1. Willis KS, Peterson NJ \& Larson-Meyer DE (2008) Int J Sport Nutr Exerc Metab 18, $204-224$.

2. Larson-Mayer DE \& Willis KS (2010) Curr Sports Med Rep 9, 220-226.

3. Holick MF (2009) Ann Epidemiol 19, 73-78.

4. Collins A (2006) PhD Thesis, The National University of Ireland. 